\title{
Maximum Species Richness: Where Is It?
}

\author{
SHIYOU LI KENT T. ADAIR
}

The Tucker Center, Stephen F. Austin State University, Nacogdoches, Texas 75962, USA

(Received June 15, 1994)

\section{ABSTRACT}

Where does maximum species richness exist? This frequently asked question has never been answered based on a large database. We examined about 10000 species of seed plants in the northern portion of the Northern Hemisphere in last 10 years. The results indicate that northwestern North America has the greatest species richness in both the boreal and temperate zones. But this great species pool has the smallest family richness and tree species diversity due to relatively recent origin. Maximum species richness exhibited largely in hydric, or occasionally in xeric, but not mesic habitats as expected. Chance is the primary factor and habitat selection is a secondary factor used to interpret this species distribution pattern.

Species diversity is a central theme in environmental studies. Scientists have accumulated much data on species diversity over the past 250 years. However, there are still some major questions: How many species exist on earth: Where are they; In which regions; In which habitats; and. Why are they there? These questions have never been addressed based on comprehensive survey. The estimated number of species ranges from 3 to 100 million (Stebbins 1981. Dayton 1991. Solbrig 1991. Gaston and May 1992. NRC 1992. Raven and Wilson 1992). However, up to date only 1.4 million species at most have been described (Raven and Wilson 1992) and there are simply not enough scientific and financial resources available at present to classify and identify all organisms (Heywood in Dayton 1991). A primary problem that must be solved before we clearly know how many spcies exist on the earth is the conceptual definition of species. It seems impossible to adopt the same species concept for all organisms because organisms are so greatly varied in structure and function. But it is necessary to use a uniform and constant species concept through a group of plants (e.g., orders, families, and genera) so that a classification system useful to human society can be established, afterall is the major purpose of taxonomy.

In the last 10 years, we have examined about 10000 species of seed plants in the northern portion of the northern hemisphere. Data sources include: field investigations, specimen observations, personal communications, and literature. The primary data for eastern Asia were largely from a Chinese national forest study conducted during 1984 1988. Data for North America were principally from literature, supported where possible, by field collections, herbarium investigations, and personal interviews. By using established methods and the same principal observer in the herbarium and field, the observational biases that often plague broad-scale comparisons were minimized. The result indicates that northwestern North America has the greatest species richness in both the

- 30 - 
boreal and temperate zones ( $\mathrm{Li}$ 1993, Adair and $\mathrm{Li} \mathrm{1994).} \mathrm{But} \mathrm{this} \mathrm{great} \mathrm{species} \mathrm{pool}$ has the smallest family richness and tree species diversity due to its relatively recent origin. This can be explained in terms of a species pool as the product of evolution, immigration, and extinction ( $L i$ 1993, Adair and Li 1994). Thus, we emphasize that the extant regional species pool is an historical artifact rather than an ecologically determinate reality.

Then what habitat supports the maximum species richness in the northern portion of the northern hemisphere? The answere is critical to species diversity conservation. Studies on regional species richness are numerous, but usually restricted to some group of plants (e. g. . trees) in a specific region. More qualitative data rather than quantitative data have been recorded on habitat species richness. The common view is that maximum species richness is found in a mesic habitat (Whittaker 1969, Barbour et al. 1980). This statement leads public attentions in species diversity conservation to the forests in mesic habitats. Unexpectedly, however, our data show that the maximum habitat species richness exhibits largely in hydric, or occasionally in xeric, but not mesic as expected. We argue that Chance is the primary factor and habitat selection is secondary in determining species distribution patterns.

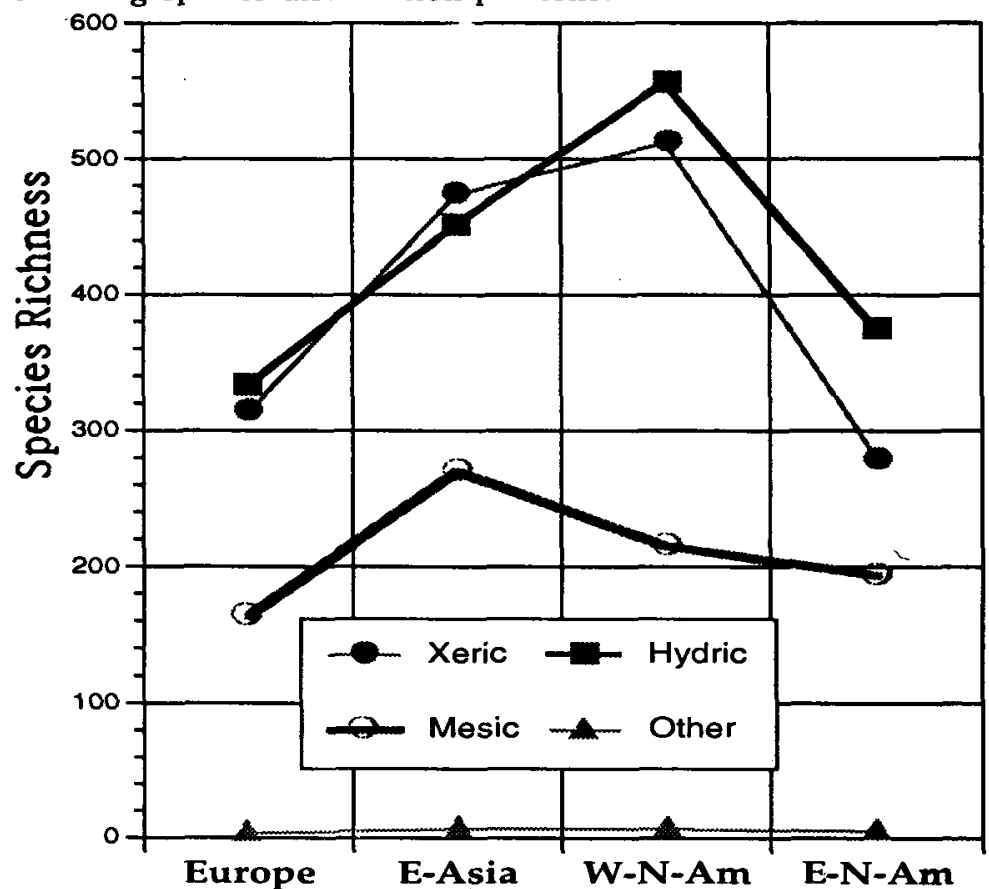

Fig. 1 Changes of species richness with habitat (entire flora) in the boreal regions (after Li 1993; E-Asia: Eastern Asia; W-N-Am: Western North America; E-N-Am: Eastern North America).

The temperate and boreal regions show similar distribution patterns of species richness with habitat (Figures 1, 2, 3, 4). Maximum richness is found in the xeric habitat (in temperate western North America and boreal eastern Asia) or hydric habitat (in all other studied areas). However, different strata of plant communities show different species richness distributions, but not the independent patterns as predicted by Whittak- 
er (1969). Tree and liana species richness is maximum in the mesic habitat, whereas herbaceous species richness is lowest in the mesic in all studied areas. Shrub species richness did not exhibit any interpretable soil moisture gradient patterns.
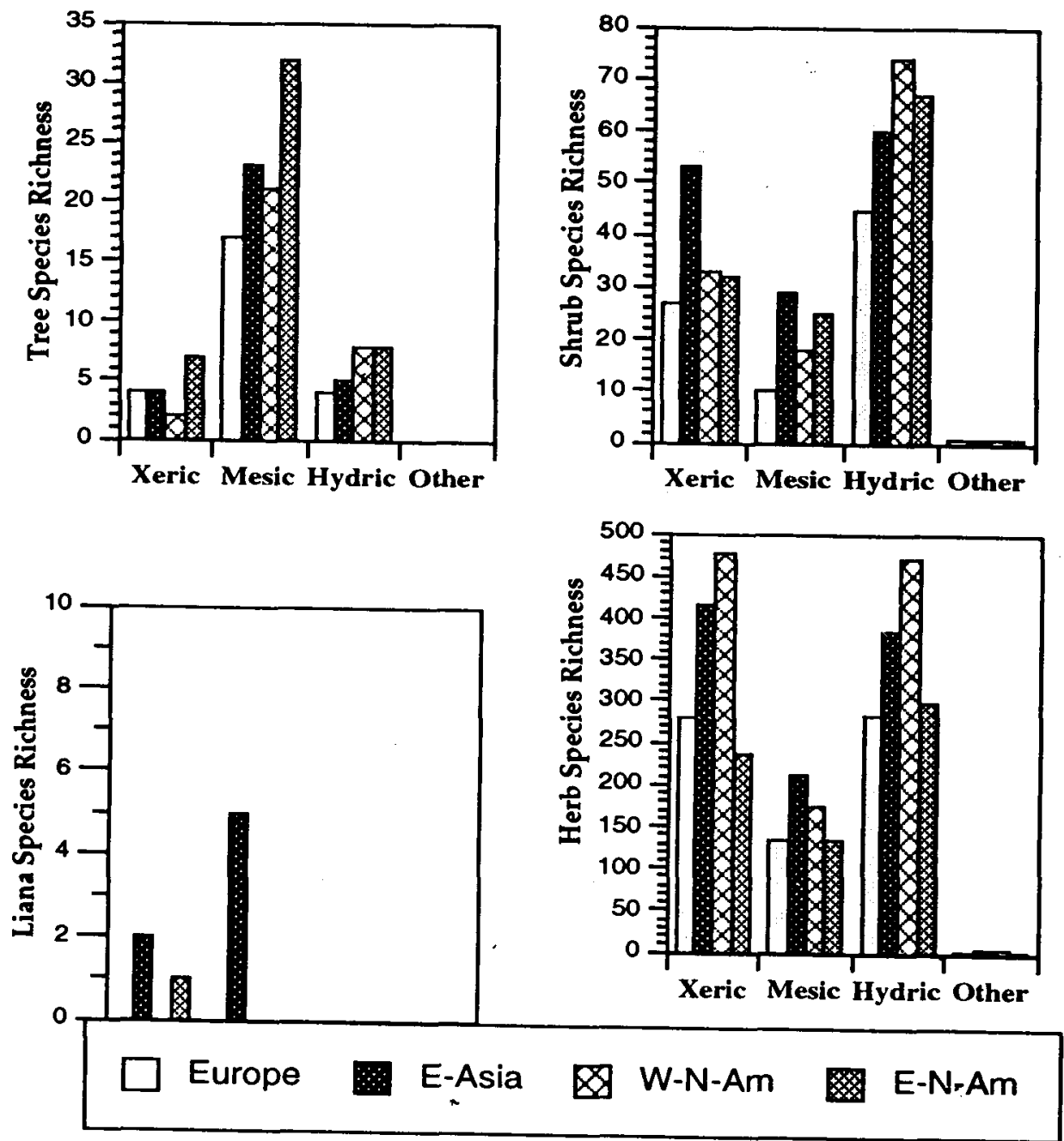

Fig. 2 Changes of species richness with habitat for each stratum of floras in the boreal regions (after Li 1993: See Figure 1).

This phenomenon can be largely explained as the result of chance first and then habitat selection. Trees and giant lianas need more energy and are highly sensitive to increasing stress (e.g. drought, frost, and flooding). Stress in hydric or xeric habitats is greater than in the mesic habitat and thus these habitats are relatively devoid of trees. The boreal and temperate forests are largely dominated by conifers, especially evergreen confers. Evergreen leaf litter decomposes slowly in these areas, and soil conditions can be less favorable in a number of ways than soils supporting deciduous forests. Also, 


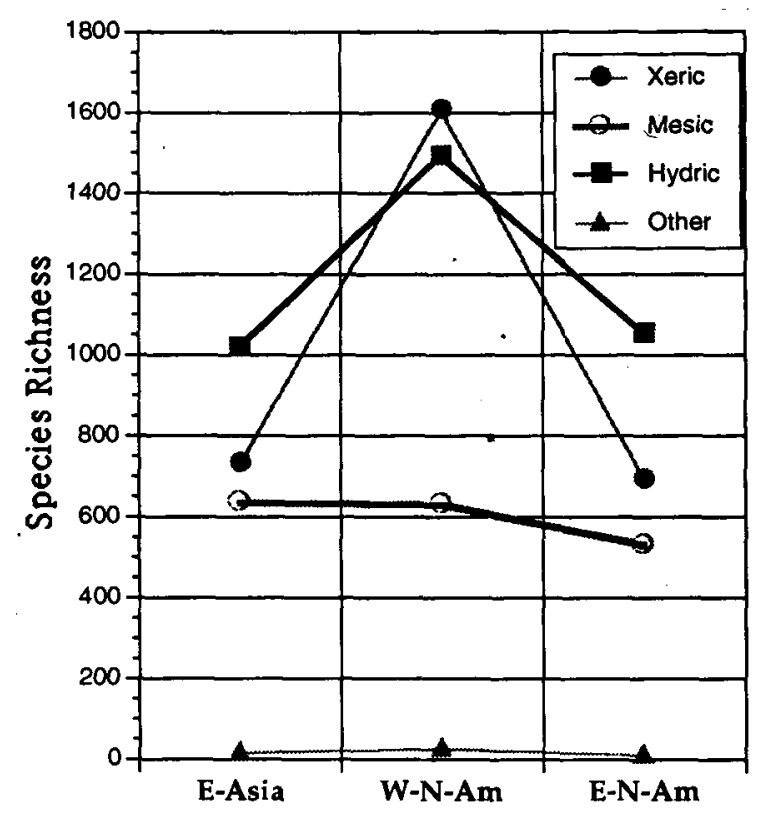

Fig. 3 Changes of species richness with habitat (entire flora) in the temperate regions (after $\mathrm{Li}$ 1993: see Figure 1).

once trees colonize in the mesic habitat, the canopy reduces the seasonal variability of those light conditions on which many herb species depend. However, apparently not all shade-tolerant species favorable to this habitat have a chance to immigrate into this community. Consequently, herb diversity is low in the mesic habitat and thus the total species diversity becomes low also because herbs predominate the entire flora.

Another interesting result supports the notion of chance first and habitat selection second. About 131 species $(85 \%)$ of the total 152 species that are common to the temperate regions of eastern Asia, western and eastern North America are found in hydric habitats. Of these hydrophytes, 106 species grow in wet soils adjacent to habitats with standing or flowing water, and 25 species are found in standing or flowing water. which includes floating, suspended, submerged anchored, and floating-leafed anchored plants. Only 30 species are found in xeric habitats and 12 species in mesic habitats. As mentioned above, trees are less developed in hydric habitat. Without a tree canopy, windadapted herbaceous species can spread widely and become established throughout hydric or xeric habitats. Epilobium angustifolium L., E. glandulosum Lehm., E. palustre L., Salix scouleriana Barra, S. bebbiana Sarg., and Hieracium umbellatum L. are good examples. They produce a large number of small, light seeds and are initial pioneers in open sites. Apparently, long distance dispersal by wind is one reason for the common taxa in hydric habitat, and this process is greatly determined by chance factors (currents). Further, of the entire flora of common species in all four temperate regions, berries are the main fruit type of shrubby species and seeds or fruits with propogules are primary in the herbaceous species. These seeds are associated with animal and bird (es- 

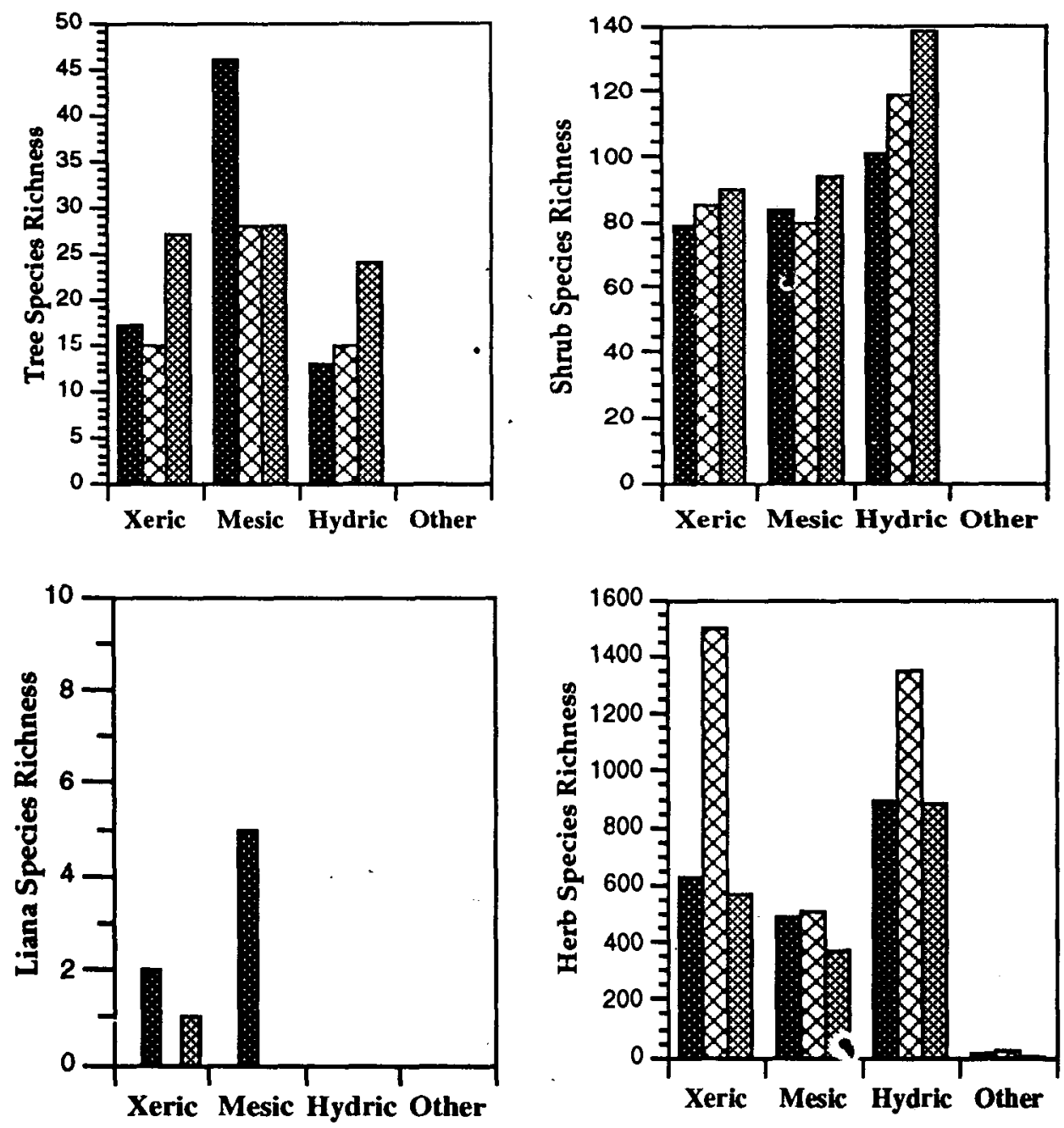

\section{E-Asia W-N-Am E-N-Am}

Fig. 4 Changes of species richness with habitat for each stratum of floras in the temperate regions (after Li 1993; see Figure 1).

pecially waterfowl) dispersal. The diospores of the herbaceous species Menyanthus trifolia L. are dispersed over long distances by a few species of birds especially geese, plus its seeds also have great buoyancy in water and are transported by both normal and flood water flows (Olesen 1987). Species of Juncus, Carex, Polygonum, Glyceria, Cyperus, and Alisma have diaspores present in the mud, which stick to the feet of waterfowl, and thus these hydrophytes are common among the separate temperate regions of the world. 
The seeds of several shrubby species of Sambucus, Lonicera, Rubus, Bryonia are consumed by birds in the early autumn, whereas Rosa. Prunus, and Euonymus are eaten by birds in the late autumn (Howe 1986). Bird and animal migration is greatly influenced by chance factors and consequently so in seed dispersal.

Therefore, the results of this study indicate that diversity of seed plant species in the northerly regions is not determined primarily by favorable physiological habitats but largely by chance factors associated with seed and spore dispersal.

\section{REFERENCES}

Adair K T, S Y Li, 1994. Seed plant species pools: the development of species richness in eastern Asia and North America. Chinese Biodiversity, 2 (Supplement) : 18 29

Barbour M G. J H Burk, W D Pitts, 1980. Terrestrial plant ecology. The Benjamin/Commings Publishing Company. Inc. Menlo Park, California

Dayton Leigh, 1991. On the saving of the species. New Scientist, January: 25 26

Ehrlich P R, E O Wilson, 1991. Biodiversity studies: Science and policy. Science, 253:758 762

Gaston K J. R M May, 1992. Taxonomy of Taxonomists. Nature. 356: 281 282

Howe H F, 1986. Seed dispersal by fruit-eating birds and mammals. In:D R Murray (ed.). Seed dispersal. 123 189. Sydney: Academic Press

Li S Y, 1993. Floristic and ecological comparisons of the continental forests in eastern Asia and North America especially in the boreal and temperate zones. Doctoral Dissertation of Stephen F. Austin State University, Nacogdoches. Texas

NRC (U.S. National Research Council), 1992. Conserving biodiversity, a research agenda for development agencies. Washington D C: National Academy Press

Olesen J M. 1987. Heterostyly, homostyly, and long-distance dispersal of Menyanthes trifoliata to Greenland. Canadian Journal of Botany, 65: 1509 1513

Raven P H. E O Wilson, 1992. A fifty-year plan for biodiversity surveys. Science, 258: 1099 1100

Stebbins G L, 1981. Why are there so many species of flowering plants? BioScience, 31(8): 573 577

Solbrig O T, 1991. The origin and function of biodiversity. Environment, 33(5): 15 38

Whittaker R H, 1969. Evolution of diversity in plant communities. In: Woodwell G M, H H Smith (eds. ). Diversity and stability in ecological systems, 178 196. Brookhaven Symposium in Biology, No. 22 